\title{
GENERAL CONSIDERATIONS REGARDING THE SPATIAL DIMENSION OF CANCER PREVALENCE IN ROMANIA
}

DOI: http://dx.doi.org/10.18509/GBP.2020.58

UDC: 303.71:616-006.6-051(498)

\author{
Iulia Daniela Nedelcu ${ }^{1,2}$ \\ Marin Burcea ${ }^{3}$ \\ Cristi Mihnea Popa ${ }^{1,2}$ \\ Adrian Gabriel Simion, 1 \\ ${ }^{1}$ University of Bucharest - Faculty of Geography, Bucharest, Romania. \\ ${ }^{2}$ Research Centre for Integrated Analysis and Territorial Management, Bucharest, Romania. \\ ${ }^{3}$ University of Bucharest - Faculty of Administration and Business, Bucharest, Romania.
}

\begin{abstract}
Cancer has become a global issue, ranking second in importance in the disease of the population, according to United Nations, after the cardiovascular diseases.

Spatialization of the phenomenon brings additional knowledge, both to identify the cancerous areas and to establish the relationships with the possible determinants.

This article presents an overview on the distribution of cancer prevalence on the territory of Romania, at the level of territorial administrative unit and at county level.

The database used is provided by the Ministry of Health, comprising both the prevalence and oncological mortality for the period 2008-2017, respectively 2008-2016, after the accession of Romania to the European Union the responsible institutions being obliged to centralize and update all medical records.

The processed database is used to perform both statistical analysis and to create spatial models, using GIS technology.

As a result of this study, a clear vision was obtained on the distribution of cancer, highlighting the carcinogenic geographical areas with maximum values, located in the big urban centers and in the highly industrialized areas.
\end{abstract}

Keywords: cancer, spatial distribution, GIS, public policies.

\section{INTRODUCTION}

Cancer is considered one of the main reasons for the disease of the population along with the cardiovascular diseases and at the same time one of the main causes of death of the population, in 2018 being registered over 9.6 million deaths, more precisely, one of 6 deaths has place due to cancer, and $70 \%$ of these situations occur in countries whose incomes are low or medium [1].

The research of this topic aims to identify the geographical conditionality of the occurrence and development of cancerous tumors for a better understanding of the causes that lead to these diseases. In this sense, there are numerous studies in the literature that try to integrate the spatial side of cancer for a broader view of the behavior of the disease depending on certain geographical conditions. The conclusions reached by the authors of the respective papers are the basis of new hypotheses regarding the possible causes of cancer cases formation and evolution, as well as the realization of public policies precisely according to these geographical disparities [2]. 
Regarding this subject, the development of Geographic Information Systems and their correlation with medical data have helped the development of strategies for maintaining the public health through surveillance, risk assessment, disease analysis and prevention [3] being represented as spatial models.

Analyzing the specialty literature, we find that the occurrence of cancer is due to the 3 major factors, namely, the genetic, behavioral factor and the environment [4]. The genetic factor has been considered the main category of triggering factors for a long time, but studies over certain time periods show that there are no major changes in the number of diseases. Even in the case of the behavioral factor, small increases are observed [5]. Responsible for $50 \%$ of the cases, it is the environmental factor, in the broad sense of the word, that is, everything that is not considered hereditary [6].

When we talk about the geographical distribution of cancer cases, geography has a special role in understanding the behavioral factors, in understanding the medical science. Once introduced in the analysis of cancer cases, GIS technology has helped to develop models for each type of cancer, later used for public policy [7], [8]. This new approach to medical data has been an important step in the distribution of oncological prevalence and at the same time the possibility of processing a huge amount of data in a relatively short time [9], [10]. The introduction of geographic information systems (GIS) allowed the development and analysis of spatial models with the spread of cancer, which made it easier to understand the relationships established between cancer and socio-economic factors and between cancer and the environment [11]. In addition, the spatial representation of cancer is an essential element in order to be able to realize or modify the public policies that have the role of preventing, combating and treating this disease [12], [13], [14], [15], [16], [17], [18]. In order to use geographic information systems and to achieve realistic results, it is necessary to analyze three main components, the geospatial component, the environmental component and the epidemiological component [19].

The lack of relevant data, verified and corrected, at a detailed level, depending on the level at which the analyzes are to be performed, is a major impediment. Knowing the current state of cancer distribution, new approaches are needed to help understand the factors underlying the tumor triggering.

\section{METHODOLOGY}

\section{Study area}

This study starts from a medical database reported at national level, at the level of the 3181 territorial administrative units that constitute the surface of Romania (figure 1). This database is represented for a period of 10 years, starting with 2008, a period that coincides with Romania's accession to the European Union (2007). This period is not chosen by chance, but because before the country joined the European Union, the medical data differed from one institution to another, and after accession all these medical records were centralized and updated by specialized persons. 


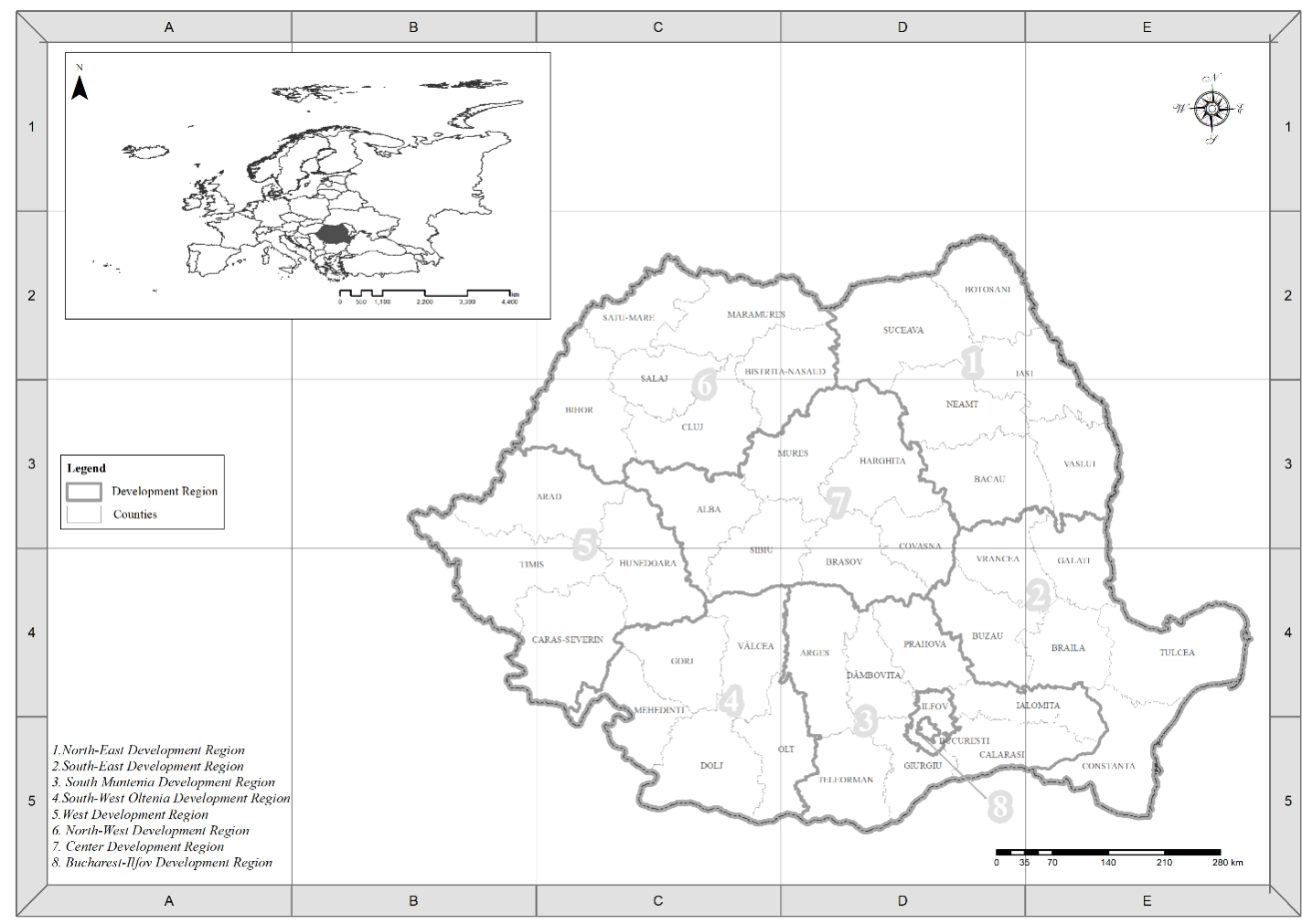

Figure 1. Development regions and counties of Romania

\section{Statistical data used}

The medical data were initially represented in the form of medical records, and then transformed into a national coverage database represented at the level of territorial administrative unit for both the number of registered cases (prevalence) for the period 2008-2017, as well as for the number of deaths due to one or more types of cancer (oncological mortality) for a period of 9 years, 2008-2016. The database is divided according to the international classification on 3 levels as follows:

- Level I Malignant tumors (C00-C96),

- Level II malignant tumors, declared or presumed to be primary, with specified locations except those of lymphoid, hematopoietic and related tissues (C00-C75); malignant tumors with poorly defined, secondary and unspecified (C76-C80) malignant tumors of lymphoid, hematopoietic and related tissues (C81-C96),

- Level III representing tumors located at the level of each organ or group of organs:

C00 - C14 Malignant tumors of the mouth, mouth and pharynx;

C15 - C26 Primary malignancies located in the digestive organs;

C30 - C39 Malignant tumors of the respiratory and intrathoracic organs;

C40 - C41 Malignant tumors of bone and joint cartilage;

C43 - C44 Melanoma and other malignant skin tumors;

C45 - C49 Malignant tumors of mesothelial and soft tissues;

C50 Malignant tumors of the breast;

C51 - C58 Malignant tumors of female genitalia;

C60 - C63 Malignant tumors of male genitalia;

C64 - C68 Malignancies of urinary tract;

C69 - C72 Malignant tumors of the eye, brain and other parts of the central nervous system; 
C73 - C75 Malignant tumors of the thyroid and other endocrine glands.

For this material, the weights of the total number of cancer cases and sex were calculated (C00-C96).

\section{Spatial modeling of cancer cases in Romania}

For the graphic component was used a medical database with national coverage, provided by the Ministry of Health regarding the total number of cancer cases (code C00-C95) total and by sex. For the realization of the spatial models, several steps have been taken, assuming the aggregation of all types of cancer according to the international classification, at the level of territorial administrative unit and the spatialization of the data in graphic form using a GIS software. Starting with the processing of the initial medical records, with the help of a relational database system RDBMS- PostgreSQL, the database used is then generated, which allows multiple records. The processing of medical records in SQL which involves the aggregation and pivoting of data is performed in an unknown interval, depending on the hardware configuration used to perform these processes. Following the processing results in tabular data exported later in .xls format in order to be used in the graphic and cartographic situations.

A final step involves making spatial models by connecting to the cancer incidence database using a GIS software, respectively QuantumGIS, in order to assign the registered value to each territorial administrative unit. The data are classified in 4 ranges of values expressed in percentages and represented cartographically in gray tones, high values with open tones, towards white, and small values with dark tones, towards black. Thus, the prevalence of cancer was represented by the total number of cases, the number of cases corresponding to the female population and the male population in the form of 30 cartographic materials specific to the period 2008-2017.

\section{RESULTS}

\section{Cancer prevalence in Romania}

Table no. 1 shows the evolution of the number of persons diagnosed between 2008-2017, total values $(\mathrm{Pt})$ and values by sex (Pf, Tm), for $\mathrm{C} 00-\mathrm{C} 96$ malignancies and structurally for $\mathrm{C} 00-\mathrm{C} 75, \mathrm{C} 76-\mathrm{C} 80$ and $\mathrm{C} 81-\mathrm{C} 96$. The structural analysis shows the predominance of the C00-C75 category, where $77.9 \%$ of the malignancies registered in Romania fall in 2000 , and $78.3 \%$ at the end of the analyzed period.

Table 1. The cancer situation in Romania

\begin{tabular}{|l|c|c|c|c|c|c|c|c|c|c|}
\hline & 2008 & 2009 & 2010 & 2011 & 2012 & 2013 & 2014 & 2015 & 2016 & 2017 \\
\hline Pt (C00-C96), persoane & $\mathbf{3 2 0 3 4 6}$ & $\mathbf{3 2 9 1 1 8}$ & $\mathbf{3 2 5 6 2 4}$ & $\mathbf{3 1 4 7 5 2}$ & $\mathbf{3 0 2 4 3 8}$ & $\mathbf{3 0 9 6 9 9}$ & $\mathbf{3 0 4 3 6 4}$ & $\mathbf{2 8 3 8 6 9}$ & $\mathbf{2 7 6 5 6 0}$ & $\mathbf{2 7 1 7 9 9}$ \\
\hline Pf (C00-C96) persoane & 157524 & 159701 & 156600 & 149920 & 143773 & 148017 & 145083 & 132649 & 129078 & 127128 \\
\hline Pm(C00-C96) persoane & 162822 & 169417 & 169024 & 164832 & 158665 & 161682 & 159281 & 151220 & 147482 & 144671 \\
\hline Pt (C00-C75) persoane & $\mathbf{2 4 9 4 2 3}$ & $\mathbf{2 5 3 4 2 5}$ & $\mathbf{2 5 3 4 7 1}$ & $\mathbf{2 4 1 8 9 7}$ & $\mathbf{2 3 2 3 4 2}$ & $\mathbf{2 3 6 3 0 7}$ & $\mathbf{2 3 2 8 3 7}$ & $\mathbf{2 2 0 9 4 7}$ & $\mathbf{2 1 7 0 3 2}$ & $\mathbf{2 1 2 7 2 0}$ \\
\hline Pf (C00-C75) persoane & 122256 & 122289 & 121376 & 113360 & 108675 & 111159 & 109737 & 102314 & 100479 & 98666 \\
\hline Pm (C00-C75) persoane & 127167 & 131136 & 132095 & 128537 & 123667 & 125148 & 123100 & 118633 & 116553 & 114054 \\
\hline C00-C75)/(C00-C96) \% & 77.9 & 77.0 & 77.8 & 76.9 & 76.8 & 76.3 & 76.5 & 77.8 & 78.5 & 78.3 \\
\hline Pt (C76-C80) persoane & $\mathbf{2 4 0 0 2}$ & $\mathbf{2 8 1 7 7}$ & $\mathbf{2 3 8 6 3}$ & $\mathbf{2 5 7 9 6}$ & $\mathbf{2 4 4 6 6}$ & $\mathbf{2 6 0 5 5}$ & $\mathbf{2 6 9 4 8}$ & $\mathbf{2 3 5 5 5}$ & $\mathbf{2 1 7 0 8}$ & $\mathbf{2 1 5 4 5}$ \\
\hline Pf C76-C80) persoane & 12974 & 14877 & 12436 & 13952 & 13507 & 14057 & 14358 & 12228 & 11227 & 11006 \\
\hline Pm (C76-C80) persoane & 11028 & 13300 & 11427 & 11844 & 10959 & 11998 & 12590 & 11327 & 10481 & 10539 \\
\hline (C75-C80)/(C00-C96) \% & 7.5 & 8.6 & 7.3 & 8.2 & 8.1 & 8.4 & 8.9 & 8.3 & 7.9 & 7.9 \\
\hline (Pt)Total (C81-C96) pers. & $\mathbf{4 6 9 2 1}$ & $\mathbf{4 7 5 1 6}$ & $\mathbf{4 8 2 9 0}$ & $\mathbf{4 7 0 5 9}$ & $\mathbf{4 5 6 3 0}$ & $\mathbf{4 7 3 3 7}$ & $\mathbf{4 4 5 7 9}$ & $\mathbf{3 9 3 6 7}$ & $\mathbf{3 7 8 2 0}$ & $\mathbf{3 7 5 3 4}$ \\
\hline Pf (C81-C96) persoane & 22294 & 22535 & 22788 & 22608 & 21591 & 22801 & 20988 & 18107 & 17372 & 17456 \\
\hline Pm (C81-C96) persoane & 24627 & 24981 & 25502 & 24451 & 24039 & 24536 & 23591 & 21260 & 20448 & 20078 \\
\hline (C81-C96)/(C00-C96) \% & 14.6 & 14.4 & 14.8 & 15.0 & 15.1 & 15.3 & 14.6 & 13.9 & 13.7 & 13.8 \\
\hline
\end{tabular}

Data source: Ministry of Health 


\section{Geographic distribution of the prevalence of malignancies (C00-C96)}

Following the analysis of the 3 images (Figure 2, Figure 3 and Figure 4), and the database used, regarding the spatial distribution of the prevalence of malignancies (category I C00C96) total, female and male from 2008-2017 it is possible to observe areas in which the value registered belonging to the last interval or the last one is maintained throughout the period, as well as areas in which the most cases are registered per 1000 inhabitants. Extreme values were registered in localities such as Bărăganu from Constanța county, $257 \%$ in 2009 , reaching $12 \%$ in the last analyzed year; Doftana from Bacau county $110 \%$ in 2008, decreasing value, $10 \%$ in 2017; Ulmu locality from Calarasi county, $108 \%$ in $2008,86 \%$ in 2017.

A number of localities were noted by values of over $25 \%$ recorded during the whole period analyzed, Ulmu (Calarasi county) $108 \%$ in 2008, $97 \%$ in the following year, reaching 86\% in 2017; Colonesti (Olt county) 63\% in 2008 reaching $120 \%$ in 2014 and falling to $73 \%$ by 2017; Gorbănesti (Botosani county), 46\% in 2008, 54\% in 2012, decreasing to $31 \%$ in 2017; Cezieni (Olt County) registers $43 \%$ in 2008, with the highest value in 2009, 47\%; Maciuca from Valcea county registers 42\% in 2008 and 44\% in 2017; the town of Iancu Jianu from Olt county registered a weight of $33 \%$ in 2008, reaching $136 \%$ in 2013 and 54\% in the last analyzed year.

The localities in which there were registered values of the weight below 5\% are: Baile Govora (Valcea county) 1\% in 2007; Horlesti (Iasi County) 3.2\% in 2017, Mitoc (Botosani County) $0.5 \%$ in 2017, Cristesti (Mures County) $1.2 \%$ in 2017 etc.

In Figure 3 we have represented the geographical distribution of the prevalence of malignant tumors for the female population from which we observed the following: Values that exceed the last threshold, $13 \%$ during the whole analyzed period are located in localities such as: Colonesti from Olt county $36 \%$ in 2008 , the largest share being registered in 2014 (57\%), and in 2017 it reaches $41 \%$. Ulmu city from CAlarasi county registers $29 \%$ of inhabitants in 2008, reaching 27\% in 2017. Corlateni city (Botosani county) registers $45 \%$ in 2014, having a downward trajectory, until 2017 reaching $22 \%$. There are a number of localities whose weight is below the first range, less than $2 \%$ printer that we remember of Vladesti (Arges county) with a weight of 0.6 cases per 1000 inhabitants in 2017, Prajești locality from Bacău county with a weight of $0.4 \%$ in 2015 , Movileni from Iasi county with a maximum weight of $1.5 \%$ in 2011, Chirnogi (Calarasi county) with $0.4 \%$ in 2017.

Figure 4 shows the geographical distribution of the prevalence of malignancies for the male population. In the following localities, a weight of over $13 \%$ is maintained for the whole analyzed period: Ulmu (Calarasi county) $78 \%$ in 2008, reaching 58\% in 2017, Brancoveanu (Olt county) 19\% in 2008, 25\% in the year 2013 and $18 \%$ in the last analyzed year, Maciuca (Valcea county) $18 \%$ in 2008 with an upward trend reaching $33 \%$ in 2017. Some of the localities with a weight of less than $2 \%$ are: Horlesti (county) Iasi) with $1.6 \%$ in 2008, Mitoc (Botosani county) 0.5\% 2016 reaching 0\% in the last analyzed year, Cristesti (Iasi county) with a weight of $0.2 \%$ in 2017 etc. 


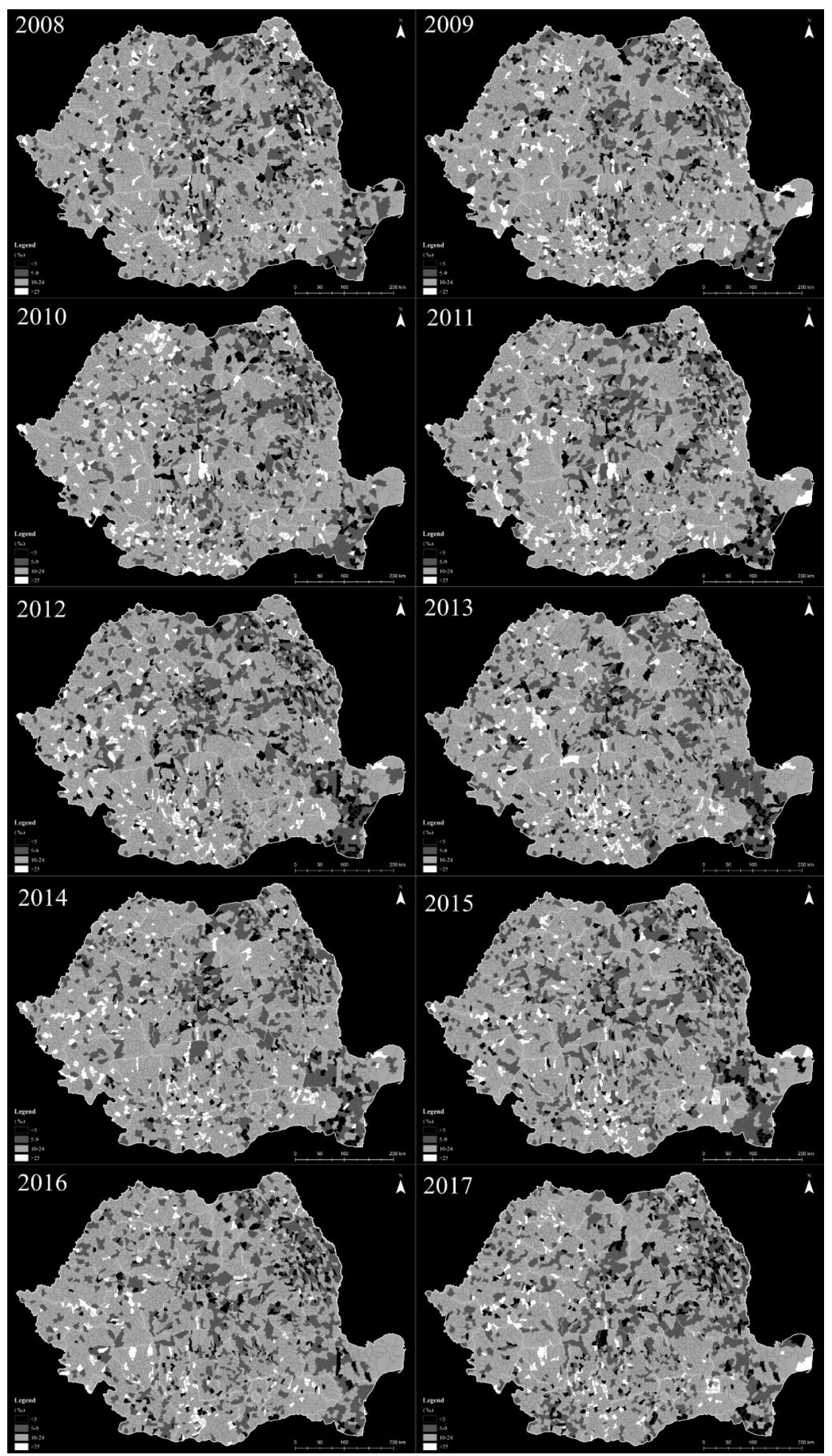

Figure 3. Geographic distribution of the prevalence of malignant tumors (C00-C96) -total (persons). Source: Ministry of Health 


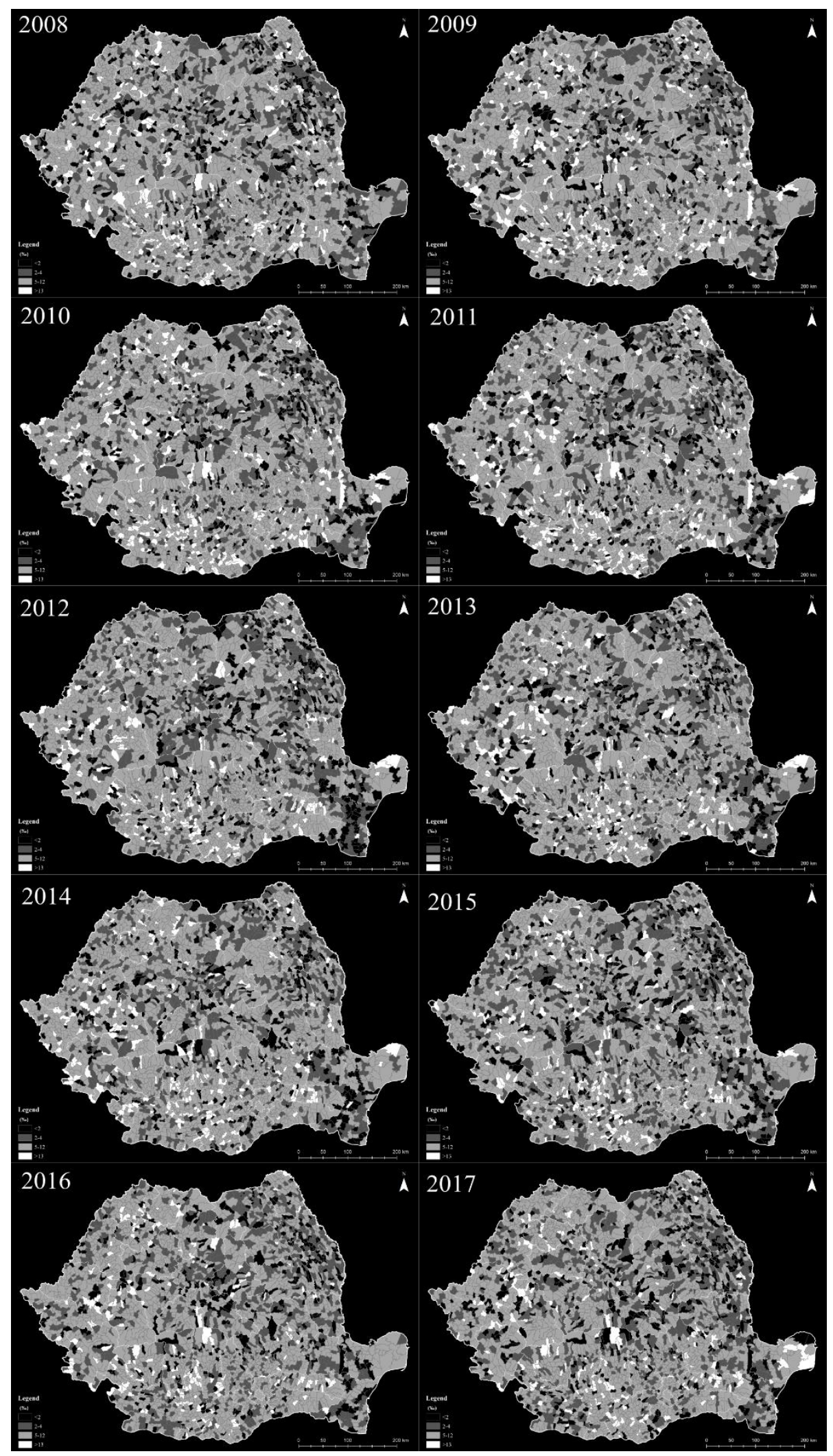

Figure 4. Geographical distribution of the prevalence of malignant tumors (C00-C96) -feminine (persons). Source: Ministry of Health 


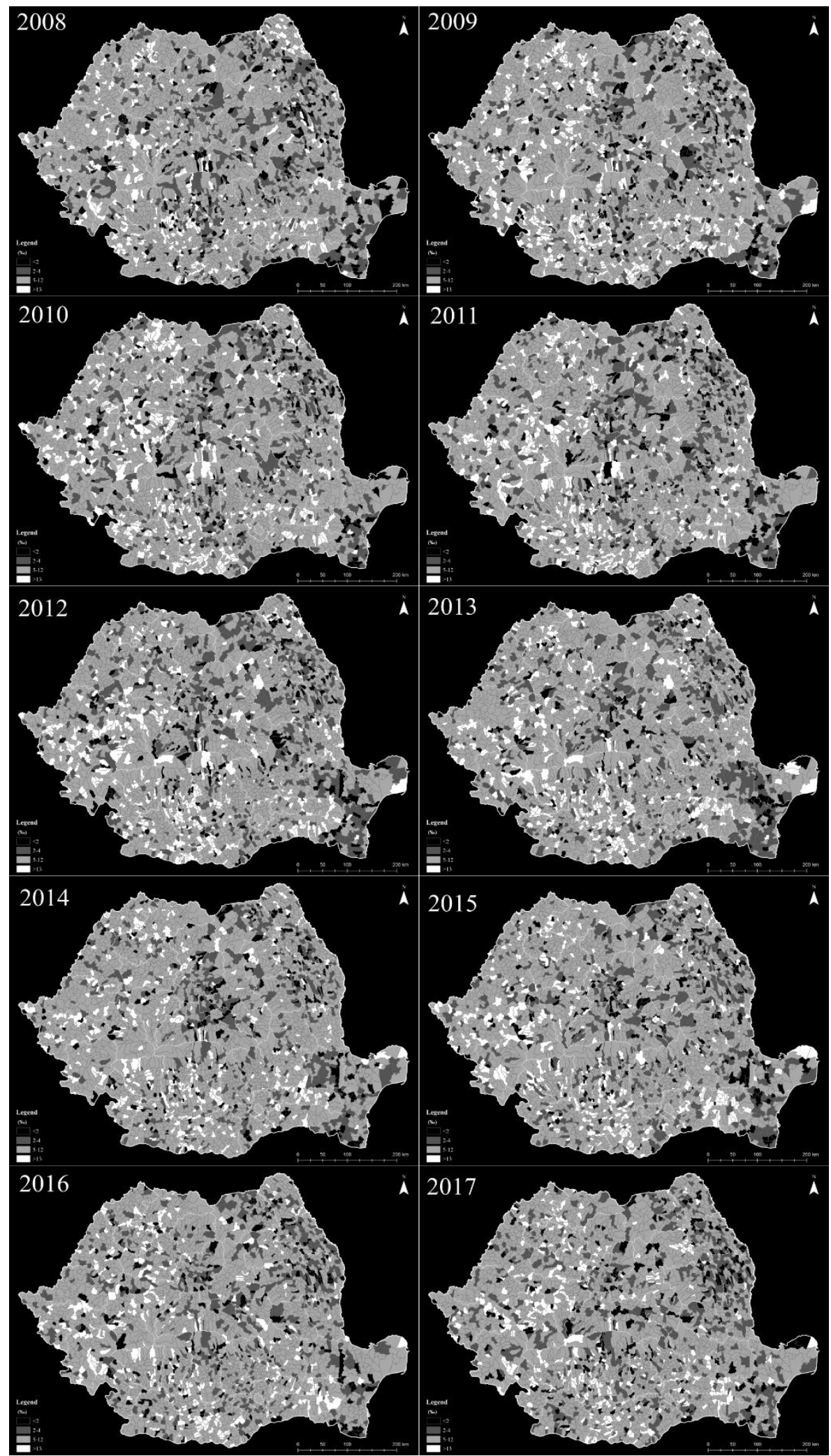

Figure 5. Geographical distribution of the prevalence of malignant tumors (C00-C96) -muscle (persons). Source: Ministry of Health 


\section{CONCLUSIONS}

A common conclusion I have observed in the specialty literature is that not having a correct database, at a detailed level for the analysis, is a major impediment. For a better understanding of the determinants of cancer and for the realization of public policies for cancer prevention and control, it is necessary to introduce new approaches, spatial modeling being one of these new approaches, bringing an increase in the understanding of the relationships of those environmental factors and cancer for the territory of Romania. This study represents the first approach in terms of spatial distribution, the lack of relevant data, centralized at the level of each territorial administrative unit made it impossible to conduct such a study.

The results show that the highest carcinogenic concentrations were in close connection with the major urban centers, but also the large industrial areas of the country, through the huge quantities of pollutants emitted during the periods when they were operating at maximum capacity.

\section{REFERENCES}

[1] WHO, 2018

[2] Xu M, Cao C, Wang D, Kan B, Xu Y, Ni X, et al. Environmental factor analysis of cholera in china using remote sensing and geographical information systems. Epidemiology \& Infection, China, vol. 144, pp. 940-951, 2016.

[3] Croner, C., M. Geographic Information Systems (GIS): New Perspectives in Understanding Human Health and Environmental Relationships. Statistics in Medicine, vol. 15, pp. 1961 $1977,1996$.

[4] Caudeville, J., Masson, J., B. Projet SIGFRIED 1: SIG Facteurs de Risques Environnementaux et Décès par cancer Integration de bases de données environnementales dans un SIG pour servir à l'analyse des disparités géographiques de cancer, 2014.

[5] Cicolella, A., Sasco, A., Valdes-Lao, D., Trugeon, A., Declercq, C., Gremy, I., Pepin, P., Guye, O., Sonko, A., Colonna, M. Analyser les in'egalit'es spatio-temporelles de cancer pour mieux comprendre le lien cancer environnement Le projet CIRCE (Cancer in'egalit'es r'egionales cantonales et environnement), 2008.

[6] https://www.niehs.nih.gov/index.cfm

[7] Hay S., I, George D., B, Moyes C., L, Brownstein J., S. Big data opportunities for global infectious disease surveillance. Plos Medicine, vol. 10, 2013.

[8] Ferlay J, Partensky C, Bray F. More deaths from pancreatic cancer than breast cancer in the EU by 2017. Acta Oncologica, vol. 55, pp. 1158-1160, 2016.

[9] Torre L., A, Bray F, Siegel R., L, Ferlay J, Lortet-Tieulent J, Jemal A. Global cancer statistics, 2012. A Cancer Journal for Clinicians, vol. 65, pp. 87-108, 2015.

[10] Jemal A, Bray F, Center MM, Ferlay J, Ward E, Forman D. Global cancer statistics. A Cancer Journal for Clinicians, vol. 61, pp. 69-90, 2011.

[11] Brewer, C. A. Basic Mapping Principles for Visualizing Cancer Data Using Geographic Information Systems (GIS). American Journal of Preventive Medicine, 2006;

[12] Jarup, L., Best, N., Toledano, M. B., Wakefield, J., Elliott, P. Geographical epidemiology of prostate cancer in Great Britain. International Journal of Cancer, pp. 695-699, 2002.

[13] Onicescu, G, Lawson, A. B., Zhang, J., Gebregziabher, M., Wallace K., Eberth, J. Bayesian accelerated failure time model for space-time dependency in a geographically augmented survival model, Statistical Methods in Medical Research, pp. 2244-2256, 2015. 
[14] Correa, P., Piazuelo, M. B., Camargo, M. C. Etiopathogenesis of gastric cancer. Scandinavian Journal of Surgery, pp 218-224, 2006.

[15] Siegel, R. L., Miller, K. D., Jemal, A. Cancer statistics, 2016 CA: Cancer Journal for Clinicians, 2016, pp 7-30, 2016.

[16] Mosavi-Jarrahi, A., Moini, M., Mohagheghi, M.-A., Alebouyeh, M., Yazdizadeh, B., Shahabian, A., Nahvijo, A., Alizadeh, R. Clustering of childhood cancer in the inner city of Tehran metropolitan area: a GIS-based analysis, International Journal of Hygiene and Environmental Health, pp 113-119, 2007.

[17] Rainey, J. J., Omenah, D., Sumba, P. O., Moormann, A. M., Rochford, R., Wilson, M. L. Spatial clustering of endemic Burkitt's lymphoma in high-risk regions of Kenya, International Journal of Cancer, pp 121-127, 2007.

[18] Jones, L., Chilton, J., Hajek, R., Iammarino, N., Laufman, L. Between and within: international perspectives on cancer and health disparities, Journal of Clinical Oncology, pp. 2204-2208, 2006.

[19] Nuckols, J., R., Ward, M., H., Jarup, L. Using Geographic Information Systems for Exposure Assessment in Environmental Epidemiology Studies. Environmental Health Perspectives, vol. 112, pp. 1007-1015, 2004. 